\title{
Linguistic Approaches in Teaching History of Science and Technology Courses through a Content Block on Cognitive Sciences
}

\author{
Olga Krasnyak \\ Underwood International College, Yonsei University \\ Correspondence concerning this article should be addressed to Olga Krasnyak, 50 Yonsei-ro, Seodaemun- \\ gu, Seoul 120-749, Republic of Korea. E-mail: olga.k@yonsei.ac.kr
}

\author{
Mik Fanguy \\ School of Humanities and Social Sciences, Korea Advanced Institute of Science and Technology (KAIST) \\ Correspondence concerning this article should be addressed to Mik Fanguy, 291 Daehak-ro,Yuseong-gu, \\ Daejeon 34141, Rep. of Korea. E-mail: mik@kaist.edu

\section{Elena Tikhonova \\ RUDN University} \\ Correspondence concerning this article should be addressed to Elena Tikhonova, Department of Foreign \\ Languages, Peoples' Friendship University of Russia, 3/379 Ordzhonikidze Street, Moscow, Russian \\ Federation, 115419.E-mail: etihonova@gmail.com
}

\begin{abstract}
History of Science and Technology (HST) courses are increasingly becoming part of core curriculums for undergraduate students due to an increased emphasis on scientific literacy. HST courses should aim to help students gain an understanding of the nature of science and should enable them to reflect epistemologically. The authors suggest teaching HST courses through several interchangeable content blocks, and herein, present the material and discussion topics that they believe should be implemented in a content block on cognitive sciences through a linguistic component. Language has a special meaning for humankind as it indicates its unique ability in the evolutionary development and in creating a new social environment. Therefore, paying special attention to the linguistic component when teaching HST courses helps students obtain a basic level of linguistic knowledge as its interdisciplinary approaches are increased through the study of cognitive sciences such as evolutionary psychology, behavioral genetics, and artificial intelligence. In order to represent a practical meaning of linguistics in the processes of constructing social environment, the authors conducted an empirical study based on the analysis of media texts. We asked 63 sophomores majoring in social sciences and humanities, who are affiliated with the Peoples' Friendship University of Russia and the Moscow State Institute of International Relations to choose 60 media texts, both broadsheets and tabloids, on social and political content. Estimating and analyzing the surveys allowed the authors to determine students' abilities to identify communicative strategies that were used in the media texts, to understand the role of the strategies in forming the social environment of a person or a group, and to recognize how using the tools of cognitive linguistics enhances sophisticated thinking and develops synergetic perceptions of every individual.
\end{abstract}

Keywords: History of Science and Technology, Linguistics, Cognitive Sciences, Evolutionary Psychology, Behavioral Genetics, Artificial Intelligence, Scientific Literacy, Critical Thinking, Media Texts, Communicative Strategies

The current educational system is facing a reality in which simply transferring information from a professor to a student no longer seems adequate. Previous methods of conveying information are now being modernized. The role of the educator has changed dramatically into that of a facilitator of group discussions, peer instruction, and the use of digital media and learning technologies. The instructor now also plays the role of a collaborator, acting as a partner in the learning process. In the classroom, students are learning how to find information on their own, and this is reflected in society as, now more than ever, people 
are able to self-learn thanks to the wide, rich, and varied information provided by modern technologies, which is changing the scientific paradigm (Kuhn, 1962). Significant help comes from big data, which can be distinctly sorted out and systematized for proper analysis and further work by using computer programs and applications.

The possibilities of the Digital Age widen the horizons for collecting, spreading, and obtaining information. One of the major advantages of using big data is the opportunity to personalize intellectual needs and find pathways to satisfy them. As the computer industry develops rapidly, new forms of working with data appear, such as quantitative computational methods of empirical research in the social sciences (Mason, Vaughan, \& Wallach, 2014). These methods include the basics of research, the design of question formulation, literature reviews, data collection and data analysis, hypothesis testing and measurements, etc. The computation of various spheres of human activity tend to not only systematize but to distinguish rational and creative issues. To avoid sinking under the overwhelming amount of information, people must learn to use it properly and efficiently.

The progression of scientific development and technological innovations and the broad access to knowledge and education have finally formed a new scientific reality that cannot be squeezed into books or categorized completely. Using a multidisciplinary approach is an efficient method for understanding the sciences considering their seemingly endless development, interaction, and the creation of new scientific fields (Parker \& Riley, 2000; Stoykova, 2014; Paveau, 2011; Wilton \& Wochele, 2011; Berardi-Wiltshire \& Petrucci, 2015). Universities are searching for ways to teach students how to think scientifically, to react epistemologically, and to gain a deeper understanding of the nature of science through multidisciplinary approaches (Hazen \& Trefil, 1991; American Association for the Advancement of Science, 1989; Rutherford \& Ahlgren, 1990; Millar \& Osborne, 1998; National Research Council, 1996). One way to achieve these objectives is by teaching History of Science and Technology (HST) courses, which are becoming increasingly common as part of core curriculums for undergraduate students.

In the HST curriculum, the authors suggest the following content blocks: 1) Cosmology; 2) Genetics and Evolution; 3) Cognitive Sciences. These blocks cover the main aspects of the sciences in their respective historical perspectives, demonstrate achievements of modern science, and indicate paths for its further development. The number of content blocks is flexible; they can be combined with extra specialties depending on the special scientific literacy requirements. Omitted fields might be added in consideration of the interests of the audience and the length of an HST course during an academic term. In addition to the aforementioned blocks, the Cognitive Sciences block could be taught separately or as a part of an HST course.

The first part of the current paper contains the theoretical background of the cognitive sciences block through the triad of sub-blocks including (1) the Cognitive Hexagon; (2) Evolutionary Psychology, Behavioural Genetics, and Linguistics; and (3) Artificial Intelligence (AI). The presented triad does not appear as a clearly-distinguished triad since each part has its own exclusive approaches and criss-crosses with others. Linguistics and AI are also part of the cognitive hexagon that will be examined through the multidisciplinary approach. Through the Cognitive Sciences block, it is easier for educators to explain how human cognitive ability was viewed throughout history, what led to the origins of this field, and what the potential outcomes are. The block allows students to look at cognition through the spectrum of certain unique characteristics that the brain possesses: language, critical and abstract thinking, reasoning, intelligence, and memory.

Linguistics is stereotypically presented as theoretical science which has few practical applications. However, understanding human linguistic capability, both written and spoken, determines social perceptions of information, its context, delivery and changeability, and precise methods and tools for working with information. Considering these characteristics is one the goals in the teaching a HST course through the Cognitive Sciences block. The presented empirical study, based on an analysis of media texts, aims to nurture students' ability to identify communicative strategies that are commonly used in the media, both broadsheets and tabloids, and to find interpretations of how language influences societies and changes them. The study is described in the second part of the paper.

\section{Materials and Methods}

\section{Theoretical Background}

Chomsky (2016) and Pinker (1994) argue that language is a human biological trait which is the part of evolutionary development, with a limitless number of expressions and transmissions. Herein, linguistic capability covers human ability (and vice versa) to obtain language, to learn, to transfer, and to develop knowledge consciously. Thus language is the human cognitive niche (Pinker, 2010; Iriki \& Taoka, 2012). Cross-linguistic analytical and descriptive works unveil the aspects of universal characteristics and the diversity of languages (Evans \& Levinson, 2009). Chomsky's 'Computability Theory' characterizes the basic property of language which is the "generation of an unbounded array of hierarchically structured mapping to the conceptual-intentional interface" 
(2016, 13). Finding proper algorithms will lead scientific perceptions of AI on to the next step. Computational mechanisms of linguistic capability, the authors believe, could be thought of as a shift in the scientific paradigm, raising humanity to the level of the Singularity (Kurzweil, 2006). These assumptions sound rather futuristic as they have not yet been scientifically proven, nonetheless, introducing a scientific way of thinking may help frame the logic of the nature of science thus enabling students to get closer to understanding the complexity of language and linguistics in its multidisciplinary integration.

The human brain is a supercomputer with limited cognitive capacity but, at the same time, the human brain has limitless possibilities to create, imagine, and operate abstractly. Given the powerful creative potential of the human mind and the rapidly increasing capacity of computers, it is clear that scientists should look for ways to empower the brain and to use computers to analyze and replicate its capacities to study, understand, and develop. Furthermore, since so much about the human brain remains unknown, largescale research investigations are required in order to unlock the mysteries it presents. One example of such an effort is the BRAIN Initiative introduced by the U.S. White House in 2013. This ongoing initiative which aims to broaden knowledge about the brain will provide funding for research that will aid in building a deeper understanding of how the human brain functions.

The authors suggest that the level of scientific and technological development usually precedes human ability to change their perceptions over time. Therefore, approaches in evolutionary psychology and behavioral genetics, which examine human behavior through an evolutionary lens, consider how the evolutionary development of the human species affects their tendencies, desires, and reactions. Linguistics, a pivotal point for human cognitive capacity, is still a contentious area among scientists; for instance, the debate over whether language is a product of the social or of the biological/genetic.. Neuroscience and genetics may help to unveil this cognitive trait and understand the mechanisms of its functioning. A new type of perception will need to be roughly systematized into the Cognitive Sciences block.

The above-mentioned categories led the authors to a 'new human' concept. This term metaphorically marks a human being with a higher rate of intelligence as a result of many spheres of human cognitive capacities such as science and art, poetry and technology, physics and philosophy, history, and mathematics. The ability of a 'new human' to integrate many different aspects together logically and to guess/predict consequences is supported by information technology development as well. Modern technologies demonstrate some amazing possibilities, including how to design and visualize knowledge in order to help people in their personal intellectual approaches and how to use existing technologies in more intelligent ways in order to obtain desired information.

The authors suggest two concepts which might be brought into class discussions: a 'new human' and a 'universal idea'. The 'new human' concept is the idea of how humankind engages with a variety of intellectual activities due to our ability to integrate information. This idea is reflected in the information integration theory (Anderson, 1974; 1981), which can be applied in many spheres of intellectual activity. Regardless of their occupation, a person should not be framed by concrete disciplines or approaches but must look beyond them. Enhancing intelligence, both human and artificial, might help contemporary societies satisfy their demand for a 'universal idea'. The 'universal idea' concept is the idea how to explain everything. These concepts could be applied to the challenges of the digital world and its transformation toward the Fourth Industrial Revolution (Industry 4.0) (Schwab, 2016).

In this paper the authors look at human cognitive ability while paying special attention to linguistic approaches. The authors suggest that the process of becoming a 'new human' is achievable in a way through which scientific and critical thinking are the preliminary conditions for moving on to the next level of development of human cognitive capacity. The Cognitive Sciences block in its multidisciplinary approach suggests that students consider this strategy.

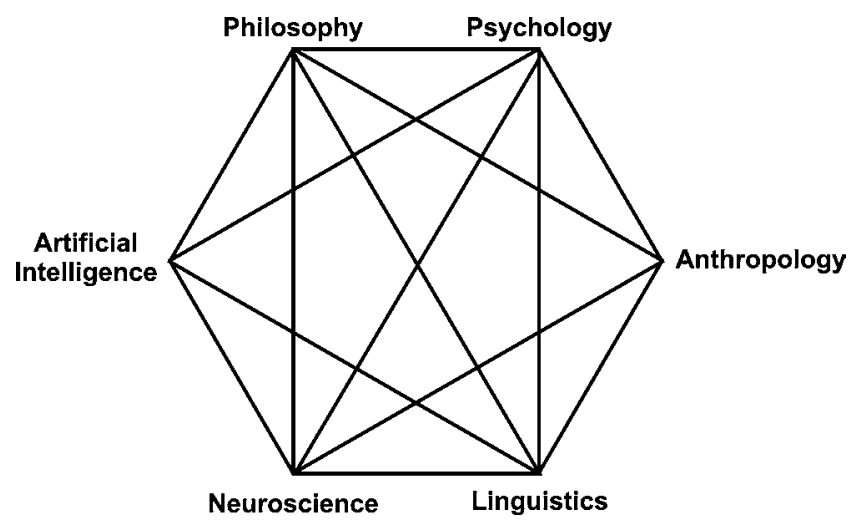

Figure 1. The Cognitive Hexagon.

\section{The Cognitive Hexagon}

The term 'cognitive' is used to describe the processes associated with the human ability to think, understand, and learn. Scholars are only able to examine the cognitive abilities of presently living species. One way to complete cognitive studies is through a multifaceted approach. The analysis of human cognitive ability is generally undertaken via six disciplines, known as the cognitive hexagon: philosophy, psychology, anthropology, linguistics, neuroscience, and artificial intelligence. By the 1950s, the sum of observations and broad scientific progress shifted to the next level. This 
shift is called the Cognitive Revolution (Miller, 2003). Students should not confuse this with the Cognitive Revolution of humankind, a period in human evolution that distinguished homo sapiens from other animals due to human cognitive capacity. The six disciplines listed are not limited in their capacities, purposes, or achievements. The model of a hexagon (see Figure 1) is conditional and flexible and depends on the issues that tended to be observed and the goals that needed to be obtained.

Philosophy should come first. Traditionally, philosophy tended to explain missing or unknown parts of human knowledge, completing them through logical constructions and highlighting the necessity of assumptions. Among many perceptions, we think that Gödel's incompleteness theorems can be taken to explain the uncertainty of the cognitive sciences and to predict their future development. The incompleteness theorems created by Kurt Gödel, one of the most important logicians of the 20th century, state that any statement can be proven if we consider that any default statement is false (Uspensky, 1994). This is a sort of indulgence, which enables authors to suggest new ideas, leaving them unafraid of the possibility of failure, and enabling them to ignore their faults and weaknesses. It is interesting to mention that philosophical conversations between Gödel and Einstein, according Gödel's later suggestion, allowed Einstein to complete his theory of general relativity, which speaks to the value of undivided sciences (Yourgrau, 2009).

Psychology is the second discipline of the hexagon, with multiple approaches toward the observation of people, their behaviour, thoughts, and feelings. For example, in the late-19th century, the results of observations of abnormal behaviour at a mental hospital by Jean-Martin Charcot, a French doctor, pushed observers to distinguish 'normal' and 'abnormal' and to come up with the concepts of the 'conscious' and 'unconscious mind' (Kumar, Aslinia, Yale and Mazza, 2011). Freud, a student of Charcot, significantly advanced the concept of the unconscious mind (Freud, 1922) and his approaches in psychology were the most influential for decades.

Behaviorism, a psychological specialization, explains the human mind as a sum of behavioral traits. John B. Watson (1913), in 'The Behaviorist Manifesto' claimed that people's behaviour, as well as that of animals, can be predicted (Logue, 1994). All of the changes in societies, including socioeconomic and political shifts, continually change people and their behaviour. These historically inevitable processes led to new disciplines and specializations as the 1970s saw a broad shift in behaviorism towards evolutionary psychology, which involved new scientific fields including genetics and neuroscience.

Anthropology, the third discipline, has its own specific characteristics. Anthropology was on the rise during the period of Imperialism from the 19th to early-20th centuries, when Western countries, the great powers, were driven by spreading mercantile interests and by hunger for political power all over the world. This period was very fruitful for observations of previously unknown facts about the outer world. Orientalism aimed to describe the differences between cultures and races. The historical reality and chain of events in the 20th century, including major controversies on race, religion, and culture, slightly shaded the topics explored in anthropological studies through these approaches. Nowadays, we think that epigenetics - the study of trait variations caused by external or environmental factors that turn genes on and off - will probably give anthropology another chance to compare ethnic groups, particularly in terms of differences when expressing their thoughts on culture, in contributions to scientific development, and in artistic achievements, as those differences are the result of interactions with the environment.

Linguistics, the fourth discipline within the hexagon and one of the most exciting pathways in science, has expanded its scientific frameworks through the modern achievements of neuroscience and genetics. Neuroscience, observing the brain through scanning, allows for the detection of those parts of the brain that are active during activities such as reading, learning, speaking, or thinking. Approaches in linguistic studies help scientists to distinguish this aspect of human uniqueness. Brain activity from childhood to old age changes, and it is astonishing that people are able to manage their linguistic capacity despite these changes in intellectual activity. This result was already known long before neuroscience appeared, but neuroscience might unveil mechanisms to enhance linguistic capability significantly. Such possibilities have led scientists to the goal of increasing human intelligence and finding ways to use human cognitive potential more efficiently.

The main approach of neuroscience, the fifth discipline in the hexagon, is to recognize the patterns of how the brain works and produces consciousness. The concept of consciousness is historically bound with philosophical perceptions of the mind-body problem, or the 'hard problem'. The rough explanation of the problem is finding consistent patterns between an organism and its ability to be conscious (Shear, 1999): are people physical beings or beings with not wholly physical characteristics; where is the border between materialism and mentality (emotions, sensations)? Some scholars have doubts that the mind-body problem can ever be solved, arguing that no matter how much is known about the brain, there is no way to precisely understand consciousness. Neuroscience tries to answer both the question of the brain and of consciousness. This is a highly interdisciplinary field that integrates approaches from philosophy and 
psychology, as well as computer sciences.

Nowadays, interest in neuroscience discoveries is growing exponentially. Big data, deep learning, enhanced intelligence, consumer-industry relations, global economics, and global politics are the stimuli for the appearance of new studies based on neuroscience. Derivatives of neuroscience such as social neuroscience, political neuroscience, and economic neuroscience are also developing rapidly. New methods and technologies of brain scanning in order to detect neuronal activity have allowed researchers to recognize the parts of the brain that are responsible for cognitive ability. The main goals of these methods are as follows: to learn how to 'read' people's thoughts; to recognize the patterns of decision-making processes, thinking, and creation; and to answer the questions of what genius and charisma are.

The sixth and final discipline included in the cognitive hexagon is artificial intelligence (AI). The idea of creating a mechanism that could solve problems as people do has created a sense of urgency in scientific circles to realize such a powerful tool. Finding an analogy with human cognitive ability is the main motivation for creating AI. The first computers and the potential to calculate and work with vast numbers of computers led to progress in AI (Benko \& Lányi, 2009). There were two dominant ways of creating AI. The first focuses on recognizing signals between neurons and reconstructs the whole scheme of neurons. This way may be represented from bottom to top, from a single group of neurons to the web, which has been the approach of most neuroscience studies thus far (Eisenecker, 1995). Einsenecker notes that the second way operates by logic, symbol manipulations, algorithms (Universal Turing machine), and a particular design of how computers need to be organized and constructed (the von Neumann architecture).

Computers and computer programs are on the rise, but AI remains far from equal to the human mind while the mind-body problem is still unresolved. A proper understanding of how the brain produces thoughts, emotions, feelings, etc., could lead scientists to the creation of sophisticated AI that will be able to compete with human cognitive ability. This concept was suggested by Marvin Minsky (2006) who proposed the idea of computing cognition in machines, based on recognizing and reconstructing patterns of human cognitive ability. Minsky also experimented with the creation of an artificial neuron web called the Stochastic Neural Analog Reinforcement Computer (SNARC), modelled after a brain (O’Regan, 2013). The problem is the vast number of neurons, as there are more than 100 billion of them in the human brain. Even modern computers are not able to operate, modulate, or simulate such a vast number of neurons.

Traditional inquiries about how exactly the brain corresponds with cognition have been the topics of philosophical debates since the 17th century. René Descartes suggested the existence of the pineal gland, a 'command center' that lies somewhere in our brains (Lokhorst, 2015). These philosophical perceptions might be considered today as slightly incorrect due to the way in which the brain works as a whole in order to achieve a state of cognition. Nonetheless, Descartes's assumptions were not senseless, but reasonable. Computers can serve as a useful analogy for the brain.

David Marr suggested a comprehensive explanation of the principles upon which computed mechanisms are likely to work. The principles of finding a solution include the following levels: 1) the computational level (Which function is provided and what can feasibly be done?); 2) the algorithmic level (How it can be done?); 3) the implementation level (Which physical parts/ components play roles in those tasks?) (Dawson, 1998). If computations help researchers to answer these questions, AI will reach the next level.

Reconstructing such simple mechanisms that people perform mechanically, without thinking, such as walking, touching objects, detecting tactile signals, and using their senses, is the path to recognizing how particular tasks might be applied to intelligent machines. Nonetheless, AI is limited to the computation of particular tasks that computer programs can manage, and.there is always a limited capacity to what can be included in a software program, whereas the evolution-formed computations of the human brain show almost limitless capacity. Even though human sensory receptors are limited, the human brain can work as a probabilistic machine: thus, interpretations of the world, as a world of uncertainty, are manifold. These multiple interpretations depend on both people's experiences and on heritable traits.

\section{Evolutionary Psychology, Behavioral Genetics, and Linguistics}

Moving from the common theoretical background of the cognitive sciences toward the disciplines, which have a more practical meaning, allows students to acquire the issues of evolutionary changes on the human brain and behavior. The human brain as a result of evolutionary changes, has developed through a vast number of changes and adaptations. Human behavior itself may be analyzed by evolutionary theory as well. Unfortunately, acceptance of the theory of evolution and its relation with human behavior is low among the general public (Perry \& Mace, 2010; Coyne, 2012), and there are many reasons for this. Scientists cannot ignore contemporary human behavior, even if it might seem irrational or nonscientific; instead, they should suggest an explanation for it. Scientific and technological development happens relatively fast, while the human brain is not capable of immediately accepting these rapid changes. In other words, human 
minds, which enable the creation of a new reality, often tend to trail slowly behind the progress society creates.

Evolutionary psychology (EP) and behavioral genetics (BG) examine human behavior and cognitive approaches through the history of human origins. The new interdisciplinary field of EP was introduced by Tooby and Cosmides (1997) to explain human behavior through evolutionary processes. They claim that 'our skulls house a Stone Age mind'; hence, awareness of the original purposes of our brains can help us better adapt our thinking to the modern scientific world. The question of what people think and how people behave might be answered by considering how early humans behaved. Bearing in mind postulations of EP, modern humans tend to solve their problems and manage situations in much the same ways that early humans did in the past (1.8 million years ago to $\sim 10,000$ years ago). If we agree that the Agricultural Revolution occurred about 10,000 years ago and the Industrial Revolution started around 200 years ago then modern society is relatively young and the patterns of huntergatherer societies have not yet faded completely away. The past of humankind can be characterized as a period of existence of small groups of foragers living far away from each other.

In the HST course some issues of modern society could be interpreted through the EP lens. For instance, obesity might be linked to the concept of maladaptation (something that was helpful and beneficial before and has become rather harmful now). A lack of food and resources in prehistorical times meant that ancient people needed to eat as much and as quickly as possible; otherwise the food would be eaten by someone else. Predators and other animals competed fiercely with humans in given environmental conditions, but that balance was broken when humans began to produce large quantities of high-calorie food. Despite this drastic change in the availability of food, patterns of eating as much and as quickly as possible remain in people's unconscious minds, even now. Thanks to human cognitive abilities to think, learn, and predict possible outcomes, we should be able to control ourselves, cutting off the unnecessary consumption of food. For some, however, obesity can result from a sort of food addiction, which in some cases can affect the brain much like a drug addiction. Such addiction correlates with the part of the brain that is responsible for reward sensations. Looking at the brain at the neuron level, connections are found between the parts that are responsible for hunger and reward. 'Disconnecting' those parts seems to be a way to break this cycle in those who experience food addiction (Nieh et al., 2015).

Society is linked with what people have created and the kinds of social patterns they should follow because of social norms. Meanwhile, social norms are changeable: the changeability of social behavior is connected with the flexibility of human cognitive abilities. The ways those changes happened and what led to them, is an old question which was brought up by thinkers centuries ago. The debate of 'nature versus nurture' is based on arguments proposed by the great philosophers of the 17th century, John Locke and Gottfried Leibniz. Locke suggested the concept of tabula rasa, referring to knowledge resulting from our own experiences (Locke, 1990). Leibniz argues that a person has knowledge that is not learned but is contained in himself/herself (Leibniz, 2000). From the perspective of modern science, the answers usually touch on both parts. Presently, science does not distinguish nature and nurture strictly, as there is a tight bond between them. Modern science suggests that we consider human behavior from a behavioral genetics viewpoint. For instance, Harden (2014), through quantitative genetic studies (e.g., twin and family studies), argues for the existence of heritable variations in adolescent sexual behavior, meaning that genetic differences shape sexual preferences. Human memory also correlates with genetics (Gedeminas Luksys et al., 2015). In a broad future perspective, this allows science to understand and to foresee human behavior much better, sizing it up via behavioral genetics and other behaviorrelated genetic means. Thus, this collective scientific knowledge by itself might shift the social environment, forming it through human advanced cognitive ability and moving society up to the next cognitive level.

Linguistic capacity, the ability to speak, not simply to make sounds, as many different species do, is a unique trait of modern homo sapiens. According to archaeological records, modern homo sapiens evolved into a species about 100,000 years ago. Nevertheless, all modern humans are cognitively similar with an ability to produce language, which roughly appeared in that period of time. Unlike vision, hearing, and spatial orientation, linguistic capacity cannot be observed or tested by itself in the animal world, only on human beings. Some animals operate using a signal system, but its design and use are different from language. Furthermore, such signal systems are not detectable by a particular part of the brain. Chomsky (1986) proposed the idea that the core of language has infinite possible expressions that have definite meanings. Chomsky argued that the process of learning a language by a child from his/her parents is a part of our nature, a sort of 'language gene', while there is no single part of the brain that can be detected which is responsible for linguistic capacity. Our linguistic capacity, which serves as an optimum communication system, is a computational system shaped by evolution.

Linguistic data can be combined with genetic data in order to reconstruct patterns showing the spread of human populations all around the world. Creanza et al. (2014) argues that there is a correlation between geographical axes and genetic 
differentiation. Geographical isolation has different effects on genes and phonemes. Human populations that live close to each other are more likely to have the same patterns in their languages. Similarly, large distances increase differences in languages and their phonemes. Tonal languages also correlate with geographical environments, and phonemes and sounds are ecologically adaptive (Everett, 2015). Taking into account the variety of factors that impact human linguistic capacity, it is possible to say that a combination of languages, genetic variations, and geographical conditions may fill in the patterns of our cognition and may confirm and complete the routes of human migrations through time.

We can see that human linguistic capacity is a very sophisticated communication system that is associated with human beings and based on human cognitive ability. Understanding of how human cognitive capacity was formed and evolved, and predicting ways in which cognition may develop is the main point of combining evolutionary psychology, behavioral genetics, and linguistics. Grasping the mechanisms of human evolution is important for understanding how this knowledge may be applied to advance computer science and to construct AI. The Cognitive Sciences block, where a few related scientific disciplines were combined in order to show their complexity and the value of uniting them, allows the authors to point out the trend toward multidisciplinary and complementary approaches in sciences. This point of view helps students progress in critical thinking, and to see the whole picture of sciences in their continuous growth and evolution.

Considering the format of this paper, the authors conducted an empirical study on cognitive linguistics. Cognitive linguistics is traditionally considered to be a theoretical scientific discipline. However, its significant empirical potential might be useful and applicable in constructing a social environment.

\section{The Study}

The present study can be used as an integrative part of the course to demonstrate to the students the impact of linguistics on comprehension and the construction of social existence. An analysis of mass media texts, both quality and popular press, helps to find specific concepts and communication strategies in the presented information stream which are used by journalists and writers to shape 'targeted' public opinion from the point of view of modern pragmatics. The goal of cognitive linguistics is to form critical and abstract thinking in students and to help them develop their skills for the effective strategic planning of speech. The formation of the scientific background in order to track the pragmatics of a discourse independently, to understand the methods and usage of certain tools for shaping how public opinion might be structured, all these represent the interconnection and mutual dependency of different sciences in their linguistic interpretation. Also, this study shows a high impact of linguistic research on the social.

The hypothesis of the current study is the assumption that the differences between quality and popular press are based on the social environment and the background of audience members. Appealing to different segments of the audience, the authors use appropriate communication strategies, cognitive patterns, and conceptual fields to conceptualize the issues and events that are reflected in texts. We assume that emotiveness, which is expressed by the audience, as well as understanding and interpreting the texts is the key tool to understand the impact of the media texts on an audience. Additionally, the study can help us distinguish whether the information was represented clearly and directly, or was offered with a wide range of allegories and special figures of speech.

To justify the above hypothesis, we asked students to choose 60 newspaper texts -30 from broadsheets or quality newspapers and 30 from popular British media or tabloids - on social and political content covering, for example, the war in Syria, the 2016 U.S. General Election (Trump vs. Clinton), and Brexit. For the quality press we selected The Times, The Independent, the Guardian, Financial Times, and The Daily Telegraph; the popular press included Daily Mail, Daily Express, Daily Mirror, Daily Star, and The Sun.

Participation in this research project was completely voluntary. The project was implemented at the end of the 2016 Spring semester. In sum, 63 sophomores majoring in social science and humanities from the Peoples' Friendship University of Russia and the Moscow State Institute of International Relations participated in the study (37 females and 26 males). The participants were informed about the aims and objectives of the study; they had also previously attended a common core course to establish a basic theoretical background related to linguistics in understanding such definitions as discourse, communicative strategies, and speech tactics. Each participant independently analyzed the selected media texts, searching for concepts and communication strategies. The analysis of the selected media texts lasted four weeks after which the participants discussed their results focusing on distinguishing the most commonly used concepts and strategies identified while reading the texts. Also, students paid special attention to the potential, the target audience, and the ability of the media texts to shape the media environment. We then conducted an anonymous survey to get students' feedback on the completed work (see Table 1) and asked them to fill it in. We asked them to select one of the answers and to add comments if needed on the righ. 
Table 1

Participant questionnaire

\begin{tabular}{|c|c|c|c|}
\hline \multicolumn{4}{|c|}{ Participant questionnaire } \\
\hline $\begin{array}{l}\text { Do you think the anal- } \\
\text { ysis of media texts is } \\
\text { informative? }\end{array}$ & yes & no & not sure \\
\hline $\begin{array}{l}\text { Do you think the analysis } \\
\text { of media texts was useful } \\
\text { in terms of its influence on } \\
\text { the formation of effective } \\
\text { speech strategies? }\end{array}$ & yes & no & not sure \\
\hline $\begin{array}{l}\text { Do you think linguistic } \\
\text { research contributes to } \\
\text { the development of a } \\
\text { synergetic perception of } \\
\text { real life phenomena and } \\
\text { processes? }\end{array}$ & yes & no & not sure \\
\hline
\end{tabular}

\section{Theoretical Background of the Study}

Cognitive activity is carried out by means of language and is generally implemented when conducting discourse. Discourse means a stream of speech, language in its constant development, reflecting specific features of a historical period and containing a variety of individual and social characteristics of both a communicant and the relevant communicative situation. Discourse reflects a mentality as well as a national, universal, and individual culture (Van Dijk, 2008). Thus, discourse is a 'language of a language,' represented as a special social given. In fact, discourse does not exist in forms of grammar and vocabulary, as a common language does. It exists mainly in texts (speech), containing particular grammar, special vocabulary, rules of word usage, syntax, and semantics. Discourse creates a special world above and beyond personality or social community. Each discourse has its own rules of synonymous substitutions, distinct criteria of truthfulness, and etiquette.

Acts of communication as such are only a part of the discursive activity that is comparable to the formation of texts 'inside the communicants.' Hence, there is a close interaction between cognitive and discursive components. Respectively, an adequate way of learning a language and linguistic phenomena goes solely through the joint analysis of cognition and communication. Cognition is the process of understanding the world, as long as discourse and communication are transferring the results of such cognitive processes or reflection on its nature and content. Both processes involve knowledge, opinions, justification, generalization, objectification of experience, and their reflection on linguistic forms.

Discourse is determined by a pragmatic situation, revealing its coherence and communicative value, specifying its implication, presupposition, and interpretation. Mental processes of communication parties, ethnographic, psychological, social and cultural rules, and strategies of generating and understanding speech also have an impact on discourse. Cognitive linguistics, based on pragmatic studies, accumulates great potential for the assessment and interpretation of emotions, shown within a particular discourse. Thus, an analysis of any discourse has cognitive elements, allowing us to identify the interaction and a vocabulary that a person uses in their speech, writing, or any other type or form of communication.

Pragmatics and purposes of newspaper texts have an impact on the audience through delivered information by using specially selected communication strategies. Communication strategies are meant to implement an intended paradigm: special patterns that continuously establish a required level of communication. Patterns of verbal behavior as well as personal characteristics of communicators, their ambitions and even appearance, are among the elements of a communication strategy.

There are several identified communication strategies. In this study, we applied the four commonly used metacommunication strategies preserving politeness as a core of communication (Brown \& Levinson, 1987): first, bald on-record (be direct); second, positive politeness (be attentive to the opponent); third, negative politeness (make negative statements in a polite manner); fourth, off-record (make statement less clear). We chose the above classification because all the represented strategies aim to cooperate and to make communication effective. The media texts that were chosen for the current empirical study were analyzed in terms of their effectiveness for communication as well as their potential to prevent confrontation while encouraging dialogue. Bald on-record and positive politeness can be called cooperation strategies whereas negative politeness and off record (indirect) represent confrontation strategies. We deliberately did not consider the strategy of direct verbal aggression, as its usage is inappropriate in media discourse. Communication strategies in a given communicative situation can be performed through a verbal strategy (for example, speech tactics), determining a verbal behavior in terms of choosing the optimal ways and means to achieve communicative goals.

The development of cognitive linguistics that relates language processes with mechanisms of cognitive information processing, the application of allegories and special forms of speech, such as metaphors in media texts, garnered specific attention. The allegorical phenomenon of a metaphor is interpreted today as a category, based on the principle of cooperation and the integration of frame structures of two different mental fields with common features, provided one mental field is deemed via another one due to the use of common space (Lakoff \& Johnson, 1980). We tend to interpret the potential of allegories as a tool to develop speech 
strategies within a specific communication strategy.

\section{Results}

Considering the length of the paper, we will present only the most commonly used concepts and speech strategies identified by participants in the empirical research on the analysis of the media texts. The students spotted the following communication strategies and relevant concepts in the quality press:

1. Off-record (indirect) strategy:

In the article "Boris Johnson says Assad must go if Syrians' suffering is to end" (Wintour, 2016) the representation of cognitive processes is implemented through the distinction between metaphor and metonymy: "We need someone to provide the boots on the ground; and given that we are not going to be providing British ground forces - and the French and the Americans are just as reluctant - we cannot afford to be picky about our allies", stated Johnson.

Militarized metonymy 'the boots on the ground,' being militaristic jargon, has a very specific context, qualifying the Syrian military operation within the concept of a 'war based on politics.' The word boots, referring to the cognitive field of 'military resources,' marks the culture-bound item a 'soldier'. Metonymy represents one part of a military uniform, while the metaphor marks the elements of one cognitive field, representing empirical perception, with the units from the other field. Such a discursive construct shows the author's wish to disassociate himself from the stated problem and negate the opportunity to solve the issues on his own.

The next broadsheet publication, 'The theater of horror' (Harari, 2015), sets an example of developing the off-record (indirect) communication strategy via the speech strategy of revelation in terms of the key concepts such as 'politics as a game,' 'politics as a theatre' and a 'war based on politics'. As Y. N. Harari (2016) writes:

It is because the Pentagon is a relatively flat and unassuming building, whereas the World Trade Center was a tall, phallic totem whose collapse created an immense audiovisual effect... We intuitively understand that terrorism is theatre, and hence we judge it by its emotional rather than material impact. With hindsight, Osama bin Laden would probably have preferred to launch the plane that hit the Pentagon against a more picturesque target, such as the Statue of Liberty. True, few people would have been killed and no military assets would have been destroyed, but just think what a powerful theatrical gesture it would have been. ...Like terrorists, those combating terrorism should also think more like theatre producers and less like army generals. Above all, if we want to fight terrorism effectively we must realise that nothing the terrorists do can defeat us. We are the only ones who can defeat ourselves, if we overreact in a misguided way to terrorist provocations.

By deploying lexical items belonging to the same semantic field as the conceptual metaphor a spectacle, theatre producers, audiovisual effect, theatre, picturesque target, theatrical gesture - and through the metaphorization of processes, the author injects a high level of emotiveness into the text. The vocabulary of the semantic field 'theatre' (Terrorists don't think like army generals; they think like theatre producers) is used to demonstrate the hypocrisy of the terrorists' position and its rejection by the author.

The negative assessment employed by veiling the concept of a war using the concept of a theatre is a stylistic device, an illustration typical for the quality press vision of the world through the prism of a theatre and a game in general:

This is what makes the theatre of terrorism so successful. Paradoxically, then, the very success of modern states in preventing political violence makes them particularly vulnerable to terrorism. An act of terror that would have gone unnoticed in a medieval kingdom can rattle much stronger modern states to their very core. The citizens, for their part, have become used to zero political violence, so the theatre of terror incites in them visceral fears of anarchy, making them feel as if the social order is about to collapse. (Harari, 2015)

Off-recording is also achieved by using context augmentation of neutral (in terms of assessment) vocabulary and vocabulary with register fluctuations. The game context involves the reader into a dramatized model of conventional reality, engaging the recipient in negative perceptions of the given concepts.

2. Bald on-record strategy:

In the article "Bombing Syria is not the whole solution - but it's a good start" B. Johnson (2015) writes: "ISIS's territory is a breeding ground of hate, spreading spores of terror over the web to infect the world. ISIS and its death cult stablemates will never be defeated until we get to grips with the concept that this has nothing to do with anything except the fact that we exist. The place is a writhing bag of snakes. But just as no British military action can be a substitute for a political deal, so no British diplomacy can be effective if we are only half engaged."

This representation of information is based on the system of conceptual metaphors related to the concepts of a 'war,' 'policy' and 'terrorism:' 'a breeding ground of hate,' 'spreading spores of terror,' 'ISIS and its death 
cult,' 'a writhing bag of snakes,' 'a substitute for a political deal' within the key concept - 'a war based on politics.' A negative assessment of the described event is achieved by using stylistically-reduced vocabulary.

The next section of the article - "This is not a kneejerk response to the Paris bombings. The proposal is not offered in a spirit of vindictiveness, or neo-con ideology" - is written with the usage of conceptual metaphors and extra expressiveness. Those are the characteristics of the bald on-record strategy. The strategy represents the concept of 'a war based on politics' and is built through the denial to show the mismatch of political declarations with happened events. Using rhetorical questions ('Who are they?' 'Whose boots will be on the ground?' 'How can we be taken seriously if we fail to join a coalition of some of our closest allies?') contributes to the accentuation of the voice of the opposed strategy.

3 . The negative politeness strategy:

This strategy is clearly demonstrated in the article 'Why you really shouldn't worry about terrorism' (Johnson, 2015) through the stylistic tools of convergence and enhancement of the semantic field of 'a war based on politics,' 'politics as a game' and 'terrorism as a movie' concepts:

I used to think our leaders' reactions to terrorism were a bit like a bad conspiracy movie. You know, those films where they start by penciling in the explosions and the CGI and, half way though, someone says, 'Oh, we better put some plot in here.' So they find the one guy in the room who has read a John Le Carre novel and he crowbars in a narrative which normally goes: bad guys bomb the good guys, then, in the race to stop the next bomb, the good guys lose their souls. <...> But actually, I've come to see that real life is a lot worse. (Johnson, 2015)

Giving emphasis to the lexical items 'a movie' and 'a plot,' the author opposes them to 'a series of exciting events,' underlining that the described events take place in real life, not in a movie, and demonstrating the danger of treating reality as a detached film.

The students came to the conclusion that, in the popular block press, real events are represented through the lens of concepts similar to the concepts that were identifying in the quality press: 'politics is entertainment,' 'terrorism is a disease,' 'terrorism is a theatre,' 'politics is a Hollywood movie,' 'politics as a game". However, the strategy of negative politeness was the only one spotted among the specified communication strategies. For instance, it is specifically used in the article "Jedis for President! The American public would rather elect Star Wars characters ObiWan Kenobi and Yoda than Hillary Clinton or Donald Trump" (Schwab, 2015), as an allusion to the Star Wars movie franchise. The title of the article gives a negative assessment to the described events, ironically characterizing the inability of the real presidential nominees to resist the fictional characters or real celebrities:

The force is strong with the American public who, in a new poll, said they'd rather elect Star Wars characters Yoda and Obi-Wan Kenobi president than the political party's two current frontrunners... Yoda trumps Republican frontrunner Donald Trump by 18 points, with 42 percent saying they'd support the Jedi in a hypothetical head-to-head matchup, while 24 percent would support Trump, according to an Ipsos Public Affairs poll... Democratic frontrunner Hillary Clinton also gets trounced by the little green guy, with 41 percent of respondents on team Yoda and 25 percent ready for Hillary. (Schwab, 2015)

Yoda (the little green Jedi master) is a phenomenon primarily related to popular culture; his use here to draw a comparison with the real nominees does not contribute to strengthening their status but rather elevates his.

In the article "Radical preacher brainwashed young men to unleash Paris and Brussels terror attacks" (Drake, 2016), beside the concepts 'politics as a game,' 'politics as a theatre,' a radical preacher has been unmasked as the terror puppet master behind the Paris and Brussels atrocities, we also see the conceptual metaphor 'terrorism - theatre'. The negative politeness strategy is confirmed by characterizing a person or group as a 'puppet' whose actions are controlled by another.

The conceptual metaphor 'terrorism - disease' was also quite widespread, as in the plague of international terrorism. The titles in British tabloids illustrate this trend: "Chief medic warns Britain: Obesity is as big a risk as terrorism to health and NHS" (MCDermott, 2015) and "How evil ISIS are like a DISEASE spreading to become a global terror group" (Millar, 2016).

We compiled the results from the surveys and observed that, in response to the first question, the majority of participants (81.5\%) concluded that linguistic analysis of media texts plays an important role. The analysis might help to unveil initial purposes of given information, to stimulate reasoning and critical thinking, and to minimize its manipulative approach on the audience. Only $24 \%$ of participants admitted that they had difficulties with the linguistic analysis of media texts. $13 \%$ were not able to address the first question but agreed that the linguistic analysis enhanced their critical and abstract thinking, teaching them 'not to follow in someone else's footsteps.' 3\% of respondents felt the analysis was meaningless and $2.5 \%$ declined to address the question.

In answering the second question on the questionnaire, $79.2 \%$ of respondents pointed out that 
the analysis of media texts helped them to establish effective speech strategies because it enabled them to deconstruct the patterns for how any strategy, when properly utilized, has an effect on society and changes social opinions and perceptions. $68 \%$ of students surprisingly noticed that they had a different interpretation of the concepts and the strategies compared with their peers. This conclusion motivated students to think about how information effects both individuals and communities. Something that was perceived as clear, understandable, and beyond doubt became uncertain upon discussing it. One of the students commented, “ [...] It's strange to see how the positive politeness strategy, using ambiguous terms and definitions, are (sic) able to interpret any information in the opposite way. I was thinking previously that only direct aggression may possible (sic) to change someone's opinion." Many students (73\%) acknowledged that studying the speech strategies and the ways they were used might be helpful in their everyday lives. However, proper understanding of those strategies requires background knowledge about non-linguistic sciences such as psychology, philosophy, history, literature, political sciences, etc. $2.5 \%$ of respondents did not answer the second question and $19.3 \%$ were not be able to answer it clearly.

The final question and additional comments demonstrated that the majority of participants (89\%) admitted that synergetic perceptions need to be implemented in order to understand changeability in the scientific paradigm. Otherwise, not all of the students will properly understand the meaning of the synergy. Some students think of synergetic perceptions as an integration of a number of scientific fields. $4.5 \%$ did not answer the question and $7 \%$ were not sure about how to answer.

\section{Discussion}

The results of the discussion among the participants allowed them to conclude that:

1. The conceptualization processes in language reflects historical and cultural backgrounds. In discourse, conceptualization changes due to individual perceptions for both authors and recipients in addition to their social and situational circumstances. The situational context represents itself as an aim of communicational and discursive strategies. Thus, discourse analysis allows us to understand how both sides interpret information. Precise results of discourse analysis might be achieved through detailing communicative strategies and speech tactics. It is important to realize contextual expectations (age, social status, gender, etc.).

2. Portraying real life in terms of popular TV shows or movies is understandable for contemporary society. However, concepts that are used in the broadsheets and tabloids differ from each other. In other words, if the mass press uses definitions such as 'politics as a game,' 'politics as show business,' or 'politics as a farce' in their common perceptions, the quality press distinguishes this concept more precisely, adding the cognitive associated models of 'theatre,' 'literature,' 'history' and, based on the listed categories, more sophisticated figures of speech. For example, the formulation of the negative image of a terrorist/terrorism, a politic/ politics, draws an audience's attention away from other situations.

3. The most important and commonly used strategic method to form an image of a social issue, its public reflection and interpretation, is the usage of the number of discursive strategies in a single media text. The British broadsheets utilize at least three out of four of the above-mentioned strategies. All this together is supposed to motivate active cognitive activity in order to understand the initial meaning of a message considering the authors opinion and semantic manipulations.

4. In spite of the fact that the analysis of media texts was meant to use the strategy of cooperation, this was finally approached through two speech tactics: (1) the uncertain speech tactic of flattery, irony, and falsehood; (2) the tactic of confrontation of threat, bullying, persecution.

5. A journalist can shape public opinion in a specific targeted direction by following the common characteristics of a person or group within society. Accepting the dominant position de-motivates a recipient from forming their own point of view, based on complex cognitive reasoning.

6. Nonetheless, the final interpretation of any given information depends on the personal characteristics of the recipient, their experiences, and their communicative competence.

\section{Conclusion}

The initial idea of choosing communicative strategies and tactics was determined by the sociocultural background of each individual, the positioning of their place in a society, their relationships with other individuals, methods for productive communication, and understanding values. In this sense, teaching an HST course which foregrounds the linguistic approach provides an opportunity to help students enhance their critical thinking and epistemological justification of the variety of spheres of their activity. The idea of a 
'new human' requires awareness of the way in which an imitation of cognitive ability is inappropriate and prevents real intellectual development in a person. By contrast, obtaining proper knowledge through the synergy of concept and understanding the complexity of human cognition and its potential can widen perspectives for further intellectual progress.

The uniqueness of language grants humans not only a tool that facilitates communication but a tool which also allows collective experiences and knowledge to advance, be accumulated, and transferred across generations thus enabling the constant transformation of social reality. The Cognitive Sciences block helps to understand, explain, and recognize existing patterns and suggest new patterns for the most effective usage of human cognitive potential. All these together move humanity to create and change its own world instead of adapting to it. Humans do not tend to evaluate methods for utilizing cognitive power; they have to recognize, instead, that the world they live in depends on their activities, their approaches, and all possible outcomes, both good and bad. This means that modern science and the scientific mind can influence the future like never before.

Education is one of the most empowering experiences humans can have. When students realize the incredible extent of their cognitive abilities they will recognize their own power and responsibility to solve the key problems facing humanity. This makes exposure to the cognitive sciences, through the medium of HST courses, an integral component of any university curriculum.

\section{References}

American Association for the Advancement of Science. (1989). Project 2061: Science for all Americans. Washington, DC.

Anderson, N. H. (1974). Cognitive algebra: Integration theory applied to social attribution. In L. Berkowitz (Ed.), Advances in experimental social psychology (pp. 1-101). San Diego, CA: Academic Press.

Anderson, N. H. (1981). Integration theory applied to cognitive responses and attitudes. In R. E. Petty, T. M. Ostrom \& T. C. Brock (Eds.), Cognitive responses in persuasion (pp. 361-397). Hillsdale, NJ: Erlbaum.

Benko, A., \& Sik Lányi, C. (2009). History of artificial intelligence. In M. Khosrow-Pour (Ed.), Encyclopedia of Information Science and Technology (2nd ed.) (pp. 1759-1762). Hershey,PA: IGI Global.doi:10.4018/9781-60566-026-4.ch276

Berardi-Wiltshire, A., \& Petrucci, P. (2015). Bringing linguistics to life: An anchored approach to teaching linguistics to non-linguists. Te Reo, 58, 59-75.

Brown, P., \& Levinson, S. C. (1987). Politeness: Some universals in language usage. Cambridge, UK:
Cambridge University Press.

Chomsky, N. (1986). Knowledge of language: Its nature, origin, and use. Westport, CT: Greenwood Publishing Group.

Chomsky, N. (2016). What kind of creatures are we? New York, NY: Columbia University.

Cosmides, L., \& Tooby, J. (1997). Evolutionary psychology: A primer. Retrieved from http://cogweb.ucla.edu/ep/ EP-primer_contents.html

Coyne, J. A. (2012). Science, religion, and society: The problem of evolution in America. Evolution, 66(8), 2654-2663.

Creanza, N. et al. (2015). A comparison of worldwide phonemic and genetic variation in human populations. Proceedings of the National Academy of Sciences, 112(5), 1265-1272.

Dawson, M. R. (1998). Understanding cognitive science. Oxford, UK: Blackwell.

Drake,M. (2016, March 26). Radical preacher brainwashed young men to unleash Paris and Brussels terror attacks. The Mirror. Retrieved from http://www. mirror.co.uk/news/world-news/radical-preacherbrainwashed-young-men-7634978

Eisenecker,U.W.(1995).AI:The tumultuous history of the search for artificial intelligence. AI Communications, $8(1), 45-47$.

Evans, N., \& Levinson, S. C. (2009). The myth of language universals: Language diversity and its importance for cognitive science. Behavioral and Brain Sciences, 32(5), 429-448.

Everett, C. et al. (2015). Climate, vocal folds, and tonal languages: Connecting the physiological and geographic dots. Proceedings of the National Academy of Sciences, 112, 1322-1327.

Franzén, T. (2005). Gödel's theorem: An incomplete guide to its use and abuse. Wellesley, MA: AK Peters.

Freud, S. (1922). The unconscious. The Journal of Nervous and Mental Disease, 56(3), 291-294.

Harari, Y. N. (2015, January 31). The theater of horror. The Guardian. Retrieved from https://www.theguardian. com/books/2015/jan/31/terrorism-spectacle-howstates-respond-yuval-noah-harari-sapiens

Harden, K. P. (2014). Genetic influences on adolescent sexual behavior: Why genes matter for environmentally oriented researchers. Psychological Bulletin, 140(2), 434-465.

Hazen, R. M., \& Trefil, J. (1991). Science matters. New York, NY: Doubleday.

Iriki, A., \& Taoka, M. (2012). Triadic (ecological, neural, cognitive) niche construction: A scenario of human brain evolution extrapolating tool use and language rom the control of reaching actions. Philosophical Transactions in the Royal Society of London, 367(1585), $10-23$.

Johnson, B. (2015, July 6). Bombing Syria is not the whole solution - But it's a good start. The Telegraph. 
Retrieved from http://www.telegraph.co.uk/news/ worldnews/middleeast/syria/12023796/BombingSyria-is-not-the-whole-solution-but-its-a-goodstart.html

Kuhn, T. S. (1962). The structure of the scientific revolutions. Chicago, IL: University of Chicago Press.

Kumar, D. R., Aslinia, F., Yale, S. H., \& Mazza, J. J. (2011). Jean-Martin Charcot: The father of neurology. Clinical Medicine \& Research, 9(1), 46-49.

Kurzweil, R. (2006). The singularity is near: When humans transcend biology. New York, NY: Penguin Books.

Lakoff, G., \& Johnson, M. (1980). Conceptual metaphor in everyday language. The Journal of Philosophy, 77(8), 453-486.

Leibniz, G. W. (2000). Theodicy: Essays on the goodness of God, the freedom of man and the origin of evil. Eugene, OR: Wipf and Stock Pub.

Lokhorst, G. (2015). Descartes and the pineal gland. In The Stanford Encyclopedia of Philosophy. Retrieved from http://plato.stanford.edu/entries/pineal-gland/

Logue, A. W. (1994). Watson's behaviorist manifesto: Past positive and current negative consequences. Westport, CT: Greenwood Press/Greenwood Publishing Group.

Locke, J. (1990). Drafts for the essay concerning human understanding, and other philosophical writings. Oxford, UK: Clarendon Press.

Luksys, G. et al. (2015). Computational dissection of human episodic memory reveals mental processspecific genetic profiles. Proceedings of the National Academy of Sciences, 112(35), 4939-4948.

Mason, W., Vaughan, J. W., \& Wallach, H. (2014). Computational social science and social computing. Machine Learning, 95(3), 257-260.

McDermott, N. (2015, December 11). Chief medic warns Britain: Obesity is as big a risk as terrorism to health and NHS. The Sun. Retrieved from https://www. thesun.co.uk/archives/health/850826/chief-medicwarns-britain-obesity-is-as-big-a-risk-as-terrorismto-health-and-nhs/

Millar, J. (2016, August 4). How evil ISIS are like a DISEASE spreading to become a global terror group. The Daily Express. Retrieved from http://www.express.co.uk/ news/world/696392/ISIS-map-spreading-acrossglobe

Minsky, M. (2006). The emotion machine. New York, NY: Pantheon.

Nieh, E. et al. (2015). Decoding neural circuits that control compulsive sucrose seeking. Cell, 160(3), $528-541$.

O’Regan, G. (2013). Marvin Minsky. In Giants of
Computing. London, UK: Springer.

Parker, F., \& Riley, K. (2000). Linguistics for non-linguists: A primer with exercises (3rd ed). Boston, MA: Allyn \& Bacon.

Paveau, M. A. (2011). Do non-linguists practice linguistics? An anti-eliminative approach to folk theories. AILA Review, 24, 40-54.

Perry, G., \& Mace, R. (2010). The lack of acceptance of evolutionary approaches to human behaviour. Journal of Evolutionary Psychology, 8(2), 105-125.

Pinker, S. (1994). The language instinct. How the mind creates language. New York, NY: William Morrow and Company.

Pinker, S. (2010). The cognitive niche: Coevolution of intelligence, sociality, and language. Proceedings of the National Academy of Sciences, 107(2), 8993-8999.

Ryan, C., \& Jethá, C. (2010). Sex at dawn: The prehistoric origins of modern sexuality. New York, NY: Harper Collins.

Schwab, K. (2016). The fourth industrial revolution. Geneva, Switzerland: World Economic Forum.

Schwab, N. (2015, December 15). Jedis for President! The American public would rather elect Star Wars characters Obi-Wan Kenobi and Yoda than Hillary Clinton or Donald Trump. The Daily Mail. Retrieved from http://www.dailymail.co.uk/news/ article-3361390/Jedis-President-American-publicelect-Star-Wars-characters-Obi-Wan-Kenobi-YodaHillary-Clinton-Donald-Trump.html

Shear, J. (1999). Explaining consciousness: The hard problem. Cambridge, MA: MIT Press.

Stoykova, V. (2014). Teaching corpus linguistics. Procedia - Social and Behavioural Sciences, 143, 437-441.

Uspensky, V. A. (1994). Gödel's incompleteness theorem. Theoretical Computer Science, 2(130), 239-319.

van Dijk, T. A. (2008). Discourse and context. A sociocognitive approach. Cambridge, UK: Cambridge University Press.

Wilton, A., \& Wochele, H. (2011). Linking past and present. A view of historical comments about language. AILA Review, 24, 55-67.

Wintour, P. (2016, July 19). Boris Johnson says Assad must go if Syrians' suffering is to end. The Guardian. Retrieved from https://www.theguardian.com/ world/2016/jul/19/boris-johnson-bashar-al-assadmust-go-if-syrians-suffering-to-end

Yourgrau, P. (2009). A world without time: The forgotten legacy of Gödel and Einstein. New York, NY: Basic Books. 